\title{
They Blog, Therefore They Think: Composition 2.0 and Blogging toward Democracy
}

\author{
Lorie Jacobs
}

\section{A Brave New (Media) World}

There has been much discussion recently about the social liberating (and limiting) potential of the internet, particularly its effect on reading, writing, and language. Much attention has been paid to "secret writing" and the young people currently in high school and college (Agger 2009). The scholarly world is practically obsessed with the attempt to conceptualize and read the thinking and writing of the so-called "Facebook Generation" who are online using social networking technologies (Barton, 2005; Ducate \& Lomicka, 2008; Hansford \& Adlington, 2009; Vie, 2008). Other arguments include the fear of the decline of discourse (Agger, 1990) and/or demise of the public intellectual (Jacoby, 1982) as well as a resurrection on both counts in the socially networked internet (Benkler, 2006). One concern that has even made its way onto mainstream media shows like the Today Show and Oprah is a growing obsession with the mundane, the off-hand comment typical in online social networking sites like Twitter and Facebook (in lieu of reasoned argument), yielding a society ever more alienated, falsely conscious, etcetera.

As one who teaches first year composition at a large university, responsible for ushering new first-year students into the world of academic discourse, perhaps I have a unique perspective on these matters. It is my contention that the social networking capabilities of the internet, specifically blogs and wikis, Facebook and Twitter, have the potential to foster critical thinking and writing, promise to usher academia into a new type of discourse for students and faculty alike. Rather than contributing to the demise of academic reason, in my view, the rise of social media signals a transition to a post-consumerist salon culture of discussion and collaboration in a true public sphere. While the potential for political-cultural transformation and re-emergence of rational-critical debate is great, without conscious examination and critical engagement we risk leaving next generations to fend for themselves surrounded by media wolves. By embracing the potential of social media within academic contexts, specifically first-year composition, we have the opportunity to shape new media and consciously engage students as emerging public intellectuals.

However, successfully working toward a new academic discourse will also require a redefinition of meaning-full text and discourse. Thus, on the next pages, through a combination of narrative and theory, I will employ Derrida to illustrate the potential of social media as a language/thought liberator. Then, I will examine the goals of the firstyear composition classroom as well as some limitations. A brief explanation of how I began using digital pedagogy helps illuminate additional benefits, particularly for this generation of students. Using classroom accounts, I will next demonstrate how my own students developed as critical thinkers and writers using by blogging in a public classroom forum. And finally, I will argue that the "digital revolution" can only take place once we fully embrace its academic potential within the institutional context of our own classrooms. Consider this a Marxist re-imagining of First-Year English, a digital manifesto, if you will. 


\section{Thinking $=$ Writing $=$ Participation}

For Derrida (1967), language is a prison, standing between the mind and the world. One of his assertions, stemming from the structuralist school of thought, is that language constructs our conceptualization of the world and thus is a prison in the sense that we can't ever view the world any other way - it traps the writer into a certain set of understandings, determined by her knowledge base, her culture, her social network, etcetera. However, Derrida as a post-structuralist, moves beyond this limited view of language and suggests that "the reading must always aim at a certain relationship, unperceived by the writer, between what he commands and what he does not command of the patterns of the language that he uses" (p. 1825). In other words, it is the reader who determines the meaning - which is not necessarily the same as the writer's intended meaning.

I concede that language can sometimes feel limiting, particularly when as a writer, I am all too familiar with the search for the perfect word or the perfect sentence construction to communicate my thoughts. However, if language constructs human conceptualization of the world it permits/enables thinking to happen in the first place. Consider briefly, the urban-legendary Sapir-Wharf hypothesis concerning the Eskimos (the Inuits are actually only one of several native languages examined in the study) and the oft referenced "fifteen words for snow" (Pullum 1991). When you have fifteen words for snow, you view snow as a much more complex topic than if you view the world with only one word for snow, or so the theory goes. In this sense it's a chicken or egg scenario in that it is difficult to tell which came first: the complex view of snow or the fifteen words. Presumably somewhere in the evolution of the Inuit language, the fifteenth word developed because fourteen was not enough to describe the vast capabilities and characteristics of snow in the Polar regions. This frequently repeated tale demonstrates that fourteen words were too limiting, a prison, if you will. But it also demonstrates the capability of language to evolve as society needs new words to describe things, actions, and thoughts and communicate with other listeners. More importantly, for all those born after that fifteenth word emerged, there are now fifteen (rather than merely fourteen) ways to think about snow, to talk about snow, to write about snow. The thinking is altered by the language and vice versa. Thinking is altered, perhaps limited, by language certainly, but more so in terms of other social functions than language itself, and on that Derrida, and his predecessor Saussure, have a point: we can only communicate with the words we know, and further, without the words, perhaps the thinking never happens in the first place. But thought is also liberated by language: When there are fifteen ways to think about snow, that sure does open a lot of possibilities for discussion! Thus, language informs thinking as much as it limits it.

But of course, the Sapir-Whorf hypothesis was rather famously debunked by Geoff (Pullum, 1991). However, the original tale still circulates regularly. I believe this occurs because it raises the existential question: which came first: The thought? Or the language? It turns out, a lot of the difference between Inuit and English stems from structure rather than vocabulary. Hence what appears to be a different word in Inuit is actually a single word with several possible suffixes and prefixes to modify the original word. We do the same thing in English with adjectives, adverbs, compound words and the like. To illustrate, in Inuit there is a word plus a suffix (quanuk) that means "snowflake" (Grey, 2008). We communicate the same information by compounding two words rather than adding a suffix to a single word. English, in actuality, has just as many lexemes for snow if not more. Even though the Eskimo tale has been distorted and exaggerated over the years, it does shed light on the evolutionary nature and multiplicity of meaning possible in language - even if no word technically exists, people fairly regularly make up new ones to accommodate needs. A more modern example of this is the new definition of the verb texting, which is in widespread use today and updated in the OED in 2005, reflective of both technological advancement and cultural shift. The verb is a much more efficient way to describe the action of sending a typed text-only message via a cellular phone. These examples are intimately connected to audience, the need for a speaker/writer to communicate to others. Which is, after all, the primary purpose of language for social beings. Language evolves to accommodate our social needs, new technologies, new cultural phenomenon.

In my case, which can also be extended to the "experienced writer," especially as defined by composition researchers (Ede \& Lunsford, 1984; Perl, 1980; Sommers, 1980) much ado stems from the writer's attempt to satisfy her reader. Because the experienced writer is aware that she must anticipate multiple readers' understandings of her words, meaning expanded, altered, or developed in combination with other surrounding words, the text, which may start out as unclear and undeveloped, is eventually shaped to accommodate reader expectations. In composition, we refer to this as moving from writer-based prose to reader-based prose. Or to echo Derrida (1967), "a certain relationship" between perceived and unperceived functions of language - the experienced writer much 
more comfortably balances what she commands and doesn't command in language use. As writing teachers, it is our job to illuminate this process so that our students might do the same.

Just trying to get this paper out is a shining example of the connection between thinking and writing and participation: I think about all these issues and theories concerning thinking, writing, social media - there are so many - and so I write to sort them out; in the process of writing, loosely defined, I think of more ideas that enrich and develop the original thread. More specifically, the act of writing helps me to develop my ideas for communication to another - it is the concern for my audience that allows me, indeed requires me, to consider my ideas further, to perform an act of telepathy between my mind and that of the reader (King, 2002). And by sharing these ideas in any public forum, I am participating in academic discourse, adding to the conversation and opening the floor for further debate.

I help my students "think-write" every day in my classes with an exercise I call "Sacred Writing Time." Students are asked to freewrite for 5-10 minutes upon arrival to class. Generally, I provide a prompt connected to the day's topic of discussion. The idea is two-fold: First, in order to develop sufficient thinking for participation in classroom discussion, I ask students to write; second, the exercise serves as a model for a writerly self, another goal of teaching composition. Thinking individuals are writing individuals are participating individuals and vice versa. Academic debate and consensus (and hence a modern democratic society) emerge directly from all of the above. And all the better if we are conscious of the process along the way....

\section{Academic Initiation and the Problem of Print}

Like many (Marx; Dewey, 1938; Freire, 1970; Giroux, 1997; to name but a few) I believe that an educated society is the first step to liberation and equality, particularly in bridging the well documented "achievement gap" between the white middle class student and everyone else. For me, participation in academic discourse, even at the first-year level, is a liberating and democratizing principal. Students become better citizens, better participants in culture, when they are thinking and writing and engaging in academic debate. I value this philosophy greatly because, in my view, first year composition is the first step in a long road toward a higher education degree. As teachers of college writing, we provide the foundation upon which their academic freedoms will be built, the initiation, if you will. Further, students, especially those who come from lower socioeconomic and/or non-white backgrounds, in all likelihood benefit from all the help they can get in unlocking the secrets of academic discourse (Bartholomae, 1985; Birkenstein \& Graff, 2007; Delpit, 2006).

Stephen Yarbrough, in After Rhetoric: The Study of Discourse Beyond Language and Culture(1999), proposes that we should drop an outdated composition studies from the curriculum and replace it with a discourse studies model. He argues that we cannot teach a "how to write" course any more than we can teach a "how to live" course (Yarbrough, 1999, p. 213). Composition can and should be reinvented into a more effective course, one that not only takes advantage of student enthusiasm, but seeks to model participation in the democratic public sphere, sought after by Giroux, Agger, Jacoby, Kellner, and others.

With pressures from the state and the public to improve higher education's ability to yield adults prepared for productive lives, universities are emphasizing critical thinking and active learning campus-wide and such dogma has spread like wildfire across the academic nation. The composition course perhaps needs a more conscious agenda, but it definitely fills an important need on the college campus and, therefore, should not be "dropped," as Yarbrough (1999) suggests. If, as Yarbrough (1999) points out, students are tied to their already held beliefs of language and culture, then the composition course becomes the perfect (if not the only) place where we might challenge and expand those beliefs. Why can't the composition course embody the discourse studies pedagogy that Yarbrough calls for? One reason is its three-decade marriage to the printed text.

Throughout my teaching career, I have found "audience as collaborator" is the most difficult concept to teach first-year students. Yet once they get it, everything else seems to fall into place. I believe that academic discourse is hard for many students to envisage, to take an authentic part in, to make a real and meaningful part of their lives, precisely because it is an abstraction, quite distant from the printed page itself. For example, at best in a traditional paper-based classroom, a student writes an essay for a teacher who is responsible for giving that student a grade and hopefully some feedback for improving current or future work. Only the teacher and maybe a few peers see and respond to the text. The student paper exists outside of academic discourse, confined to the borders of the 
classroom. The printed paper, regardless of prompts or instructions requesting a specific audience, is essentially intended for the teacher and no one else. And in other classes across the department and the disciplines, this is even more likely to be the case, whereas few instructors encourage revision or formal peer feedback. So how then, can a student fully understand how her words might be received and shaped by an audience? The student paper becomes little more than an exercise in pleasing the teacher. There is not much authenticity in this model, little for students to take with them beyond the classroom and into their daily lives. Certainly many students do just fine. But perhaps we and, by extension, they can do better.

In order to provide the academic initiation of first-year students so that they may eventually become thinkingwriting-participating democratic citizens, there is a lot to address in the first-year composition classroom and, like most things worth doing, it is far more easily said than done. Perhaps it will help to summarize, briefly, what students can and should learn in the postmodern composition (how to be an academic writer) classroom. Students must encounter (master?):

- Discourse itself: recognizing and participating in the ongoing conversation within and without the university.

- Conventions of academic discourse.

- Means of persuasion to be able to participate and achieve discoursal goals more effectively.

- Audience awareness.

- Critical thinking: self-questioning, questioning authority and assumptions.

- Inherent nature of language to posit social action.

- Embracing difference and dissensus as a means of identifying consensus.

- Benefit of collaboration and negotiation in yielding a more effective discourse.

- Concept of language as creation of meaning rather than mere representation of meaning.

- Learning processes: Consciously reflective, student-centered approaches help achieve all of the above.

To truly accomplish these goals, the composition classroom needs an upgrade. Thus, what I shall propose in the remaining sections of this essay is that the best way, perhaps the only way, to include these goals in the future composition classroom is via Web 2.0 technologies, socially interactive user-defined media, where participant is author and expert collaborating with other author-experts. Think of it as equal parts rhetoric, critical pedagogy, and discourse studies, all existing and rehearsed pedagogical approaches. But with the addition of new media to the equation, the student, and perhaps the academy, benefit by (literally) becoming public intellectuals, active educated participants in the democratic public sphere. This, I believe, allows my students to achieve multiple goals by integrating what they learn in the writing classroom into their daily lives, making participant education a reality.

\section{Getting from Point A to B}

I'm a Gen-Xer, a member of the original "slacker" generation. The term was invented to describe us in our youth (circa 1991) and stuck around long enough to define us. We did not grow up with computers; at least not the way kids do today, though many of us had the first video game consoles as children and used Commodore 64's in the school library. We wrote our papers on old DOS systems and used easily corruptible floppy disks (that weren't really floppy). Most of us were in high school, college, or just beginning our careers when AOL popularized the chat room. Many of us have tried online dating at least once. We started with dial-up but were also the young adults who invented Google and Yahoo, who populated Silicone Valley at its height, who made millions selling start-up internet companies and created both the internet boom and its subsequent crash. We are not Millennials, or Generation M, as those born after 1980 are affectionately called. We are the generation sandwiched in between Boomers and Millennials, adults who were born between 1960 and 1980. We invented blogging.[1]

I bring this up because a lot of attention is paid to "kids today" and what they are doing online and on their phones in the way of "secret" writing (Agger; Hansford \& Adlington, 2009; Jeffrey T. Grabill \& Hicks, 2005; Lunsford, 2006). And some of it smacks of the usual generational conflict I remember suffering through when I was a teenager and young adult: "You kids today, all you want to do is listen to grunge and hang around coffee shops and internet cafes...". Remember the television sitcoms Seinfeld and Friends? That's us. Coffee shop slackers. And it wasn't so long ago older people were trying to figure out what Gen-Xers were all about and who we were going to become. Now, the conversation has turned to the Millennials, as expected - and truth be told, I find myself on occasion raising my metaphorical cane to the sky and pleading with unknown powers, "What's with these kids today?" 
Part of the fascination and frustration is the sheer voracity with which Millennials have embraced and overwhelmed new media technologies like Facebook, YouTube, blogging, Twitter, and the like. These social networking and interactive technologies where users create the content has become known as Web 2.0. This is not news, I realize. In fact, you can catch a story on the major network news pretty much any day of the week on usergenerated media and how it is redefining "kids today" along with everyone else. Not so long ago, Oprah dedicated an entire hour to the phenomenon of Twitter (Winfrey, 2009). Nearly every television program has its own Facebook fan page. Networks regularly solicit viewer participation via new media channels. It's everywhere and rapidly taking over the world. I have never felt so plugged into the Matrix.

All grown up now, I have been teaching for just over six years in the English Department, mostly first-year composition. I am a self-reflective teacher, striving to build a better classroom, a better learning experience for my students. Since I'm a doctoral candidate, too, I am well versed on all the theory of teaching composition: I read the journals, I help develop departmental rationales for learning outcomes, and I actively search for new ways to assist my students in achieving them. Several years ago at the beginning of my teaching career, I started using message boards and WebCT (now Blackboard) as an option to keep my students busy if I needed to attend conferences or otherwise miss class. It started as a way for a young teacher to keep the conversation going from afar. It worked! And at the time it was "cutting edge." As time went on, I gradually incorporated more and more online learning in my face-to-face classroom. Today, I use a hybrid teaching model: mostly face-to-face meetings, but some are entirely online, the class is "paperless," and all formal assignments take digital form.

I really like this hybrid model. Perhaps more importantly, they really like it - most of them, anyway. For me, embedding social media into my face-to-face classroom yields more actively engaged students and thus, aids those students in thinking and writing and participating more and better, which shall be demonstrated in the next section. For students, I imagine the benefit is the same, though I suppose they are likely to be less conscious of this. The "like" for them probably comes from the interactive, multimedia nature, the free-form feel, the fact that using social media is less like work and more like play. The future of composition, Composition 2.0, if you will, is moving away from the static academic research paper and moving toward the dynamic academic conversation. If you'll indulge me, Dear Reader, I would like to explore this idea further with a few examples from my own classroom. It will help to understand the assignments my students work with, so I will describe those as well.

\section{Blogging toward Academic Discourse}

In my department, a common writing assignment is the "reading journal" or "summary-analysis" which is a brief summary of the assigned text plus an analysis and/or response. Response should move beyond what a student likes or dislikes about a text and engage reasonable consideration of a text's purpose, audience, methods, and so on. There are two correlating goals: provide a means for students to prepare for in-class discussion while encouraging an interaction with, among, and between texts. Through this common assignment, students should begin answering back to an intangible author and making connections between their worlds and those of others.

In my class, students are asked to post their reading journals online on the Discussion Page of our class blog, http://Revisionary.edublogs.org. In the beginning of the semester, I provide a discussion question for the student to respond to. As the semester progresses, students take turns "hosting" the blog for a day and they write a brief exploratory essay plus two open-ended critical questions about the required reading or a related issue. Each nonhosting student chooses one of the host-student's questions (there may be as many as six available at any one time), writes her online reading journal-esque response, and posts it online in the comment section of the blog, prior to the next class meeting. They choose which texts interest them, which questions interest them, and as a result which academic conversations they want to lead and/or participate in.

Allow me to illustrate: For the following selection of student writing, the assigned reading was Eighner's "On Dumpster Diving" (1994), a first-person exploration of modern waste and consumption through the view of someone who was once homeless. Since "On Dumpster Diving" appears very early on the syllabus, and to help students get the idea, I wrote my own brief exploratory essay discussing the text and posted the following question: "In par. 6, p. 455, Eighner explains, 'I have learned much as a scavenger. I mean to put some of what I have learned down here, beginning with the practical art of Dumpster diving and proceeding to the abstract.' Do you think Eighner's purpose goes beyond educating his readers? What other purpose does he have?" (Jacobs, 2008, September 
2). Following are a few sample student responses:

hxt7815 - Posted: Wed, September 3rd 2008 11:48 PM

As Eighner stated "I mean to put some of what I have learned here." Most of his article discussed of what things can be and can usually be picked up in dumpsters. Actually, his real purpose of writing the article is not just to tell his readers that can is a good food from dumpsters; as the article goes on, the author begins to search reasons why the trash was littered and even stories behind them. Here he comes to some sentimental discussions inspired by the dumpsters; as stated in the question "beginning with the practical art of dumpster diving and proceeding to the abstract." So in the end of the article, Eighner pointed out that not everything is worth acquiring. This is an abstract experience in life. However, I still feel that the author is educating his readers; what I mean is that he is not to teach how to find edible garbage, but to teach them a life theory.

This is also a belief I hold in my personal life, and I can feel a strong resonance from this text. Once upon a time when I was a little student, possessing almost nothing myself, like the author, was offered free fruits in front of the classroom by my teacher. Little children besides me rushed to the front as if they have never eaten in their whole life; and in a minute, the fruit basket is empty, and some of my classmates are still fighting fiercely for some extra ones. But I can't see any value in their behavior because everybody has apples in their homes.

Therefore, while I hold the same belief as the author, this article may play a role to me as an acknowledgement of my personality and an encouragement of my life. But for most people, I still believe, this article is just a lesson on life philosophy.

"antijazz" - Posted: Thu, September 11th 2008 10:40 PM

On first read of the essay, it appears the Eighner is merely recounting his past experiences as a "Dumpster diver" and passing on his skills to the audience. However, whilst reading it a second time I noticed that there was a deeper, stronger message behind the story that Eighner was trying to portray; 'another man's trash is another man's treasure' is the phrase that comes to mind. Eighner brings to light the wasteful nature of people in today's society where food is discarded 'for minor imperfections' (Eighner p.503) when in reality there is nothing wrong with the item it just isn't as 'pretty' as the desired.

Eighner talks about scavenging Dumpsters in more affluent areas, particularly around Colleges where students tend to 'throw everything out when they move at the end of a semester...and since it is Daddy's money...' (Eighner p.504) they tend not to think about what they are throwing out; thus proving the wasteful nature of today's society where people take for granted what they have because they never have to think about where their next meal or pair of jeans comes from (Jacobs, 2008, September 2).

In these samples, an excerpt from a longer series of posts, students engage with the text, quickly addressing two of the greater messages behind the seemingly straightforward prose: that there is a social stigma against scavenging, even if items are carelessly discarded; and Americans (perhaps this can be expanded to "people," because the first student is referring to events in his native China) are quite wasteful and spoiled as a group. Students write about the text and thus learn from it. In this example, early in the semester, students have not yet developed the interactive nature that differentiates online writing from traditional paper-based writing, so essentially they have copied and pasted to the online forum, what they likely would have turned into the teacher in a paper-based course. Nor are they moving beyond the text itself or their own personal knowledge. But, it's only week two in a 15-week course - they will get there.

Here, it is enough that they model for each other the structure and style of academic writing. In my experience, the more advanced students, those already comfortable with the basic conventions of academic argument, are generally the first to post (students have a great deal of choice as to when they want to respond). Initial posts serve as a baseline for other students to get the idea as they develop critical thinking and writing skills. As the semester goes on, along with the benefit of classroom instruction, students who were less comfortable using reason and evidence to support claims at the start of the semester, eventually learn to do so, in part by imitating the work of more advanced peers.

Later in the semester we moved on to an examination of media influence in the 2008 presidential election. Students were reading critical essays concerning the role of media in politics as well as paying close attention to the issues under debate between Candidates Obama and McCain. In this specific instance, the text under discussion is Huxley's 1958 "Propaganda under a Dictatorship" (reprinted in Kirszner \& Mandell, 2007). The following exchange picked up on a new page after there were enough posts to fill up the first one - in other words, this is one of many online discussions that went on for several days, even after the "homework" was completed and course requirements were already met. Miss Lopez is making a comparison between Hitler and Castro, neither of whom were discussed in class. It was her week to act as discussion leader, although she had already posed the question in a previous post and gotten several replies, thereby successfully completing the assignment. So this is simply spontaneous inquisitive 
discourse, beyond course requirements, where she adapts to peer responses and further refines her thinking, on her own, without prodding from an instructor or the promise of assignment points:

"rosielopez131" - Posted: Tue, September 30th 2008 4:48 PM[2]

Fidel Castro is very similar to Hitler's dictatorship not because he promised race superiority instead he promised social equality, and a better economy and has promoted a strong feel for nationalism that in a way isolated them from the rest of the world's ideals. Hitler "nationalism" or "nativism" is comparable because in his speeches he appealed to the audience by calling out to the German people. His extreme repugnance to the Jewish people is very obvious because he attacked them every time he gave his speeches ,but surrounding those attacks he said that Germany's economy would be better, that the purity of Germany would prevail, and the German people would live better lives (Stein). Castro's statements are similar because they [both] appeal to the public ... and used media and technology to disperse their manipulating thoughts.

"bje1486" - Posted: Wed, October 1st 2008 4:14 PM.

I guess I can't really agree with the Cuba regime idea. Both of the dictators were very harsh and misunderstanding of the people in their countries but I don't see the comparison between the two. Hitler practiced primarily military strength in his regime and didn't have much to do with a strong national economy. He was like the little kid who just wanted to control, control, and control. Castro however has never tried to control another country. He is primarily concerned with the economy of his country. He never actually invaded another country unlike Hitler.

"rosielopez131" - Posted: Thu, October 2nd 2008 10:46 AM

Ok, so, I think we can all agree that Hitler and Castro have their differences and similarities. I was not trying to say they are exactly a like. I was trying to compare a past dictatorship with a recent one. And about the national economy comparison, check this out: http://www.ess.uwe.ac.uk/genocide/statements.htm ... look under Hitler's Closing speech at the Nuremberg Party Conference, 1938 (12 September), and Hitler's Speech to the Reichstag, 30 January, 1939:.....Basically blamed them for economic problems and if they were gone there would be better economy in Germany and worldwide. You are completely right about Hitler being a "little kid who just wanted control, control, and control", but again just trying to make past and present comparison.... Hopefully we can move on. I will not bring it up again.

"bje1486" - Posted: Thu, October 2nd 2008 5:18 PM

.... I was thinking of this in the class today do you guys really feel like we could be headed towards this type of government in the states? I don't necessarily agree with the idea that Bush would become the next Hitler but the conditions are right. the economy is in a slump and the next ruler only has to convince the people that they will get us out of the depression. We have no idea that the next president won't control our country just as Hitler did. Just as I said before, it would be really easy to brainwash the masses at a time like this.

“rosielopez131" - Posted: Fri, October 3rd 2008 2:36 AM

Wow, having another Hitler. When I heard Mrs. Jacobs say that in class I was a bit astonished -no one wants to hear that - ,but then I thought a little [more deeply] and it is true in the sense that when presidents are being elected they try to convince the masses that they are just like them, that they can lead them into a better future, and ,today, can drastically change the "slump" in the economy. Politicians....they can get so caught up in their election campaign. It is scary to think that they -in a way- persuade you in passionately agreeing with their statements. It is extremely similar to manipulation so might as well call it that. Politicians manipulate the masses into agreeing with their statements. I mean unless you know a little bit about economics you don't know how tax cuts in private corporations effect you or if you agree with the reasons are for the government to take funds out of our generation's social security. I don't even really know and I like to watch the news! Like we all agreed in class, in order to present a case or give argumentative statements you have to pretend like you know what you are talking about. Politicians do just that , but do they really understand the public or do they just really want to get elected? What do yall think?

"bje1486" - Posted: Fri, October 3rd 2008 10:14 AM

Another point that made more sense to me was last night when I was watching the Vice Presidential national debate, it became evident that some of the platforms that the two candidates stand for will not get accomplished. When the question came up about whether either candidate had any platforms in the campaign that they could not keep, Joe Biden told everyone of a couple that he could not keep. All that the politicians have to do is make some silly claim that they will lower taxes or end abortion and they have everyone on their side. But what happens when someone asks which platform they cannot uphold? They slowly change their opinion and pretty soon their campaign does not have the same views and agenda in which it started with. This is quite scary if you really think about it. It happens all the time.

"chasenwilliam" - Posted: Fri, October 3rd 2008 10:14 AM

Politician's are in the business of being in power. They will and often do exploit the ignorance of the masses who have a vote. It is up to the voter to be informed on topics and have their own ideas about what they want to see happen. I think most people in America are completely stupid when it comes to politics (yes, they really are, I promise) because they feel disconnected from the process. They believe that their one vote does not matter. Most of them are correct, too. If you live in a Red state and want to vote blue, oh well, your vote will be counted in number, but it will not count in worth due to the 
outdated Electoral College system..... America needs to move to a pure popular vote. If that were the case, Al Gore very well may have been our president for the last seven and a half years.

In this rather long and at times heated discussion, they bring in at least a dozen cultural references unique to their own individual understanding of the world and the texts around them. Not only are they expanding and developing meaning from the Huxley essay they were assigned to read, they are building upon what their peers add to the conversation. Here, they are acting out Derrida's (1967) exploration of textual meaning in multiple ways: 1) by sharing their own unique understanding so that others may grasp their ideas; 2) by adding and extending into their own "libraries" of information - whatever it is that they have read or watched or talked about that has helped them reach certain conclusions; and 3) by taking in and responding to the input of their peers, which in turn expands their original ideas. It is the exchange in writing via a public forum that enriches their thinking, ensuring faster and more meaningful learning of course concepts.

In addition, students get a real-world understanding of how readers interpret their own texts. Taking a closer look at Rosie's second post, she states, "Hopefully we can move on. I will not bring it up again." This is a one sentence "retreat" because she fears her first post was taken out of context by her peer bje1486. Rosie may be acting out a gender construction here, backing off a bit so that she doesn't come across as "pushy." Or perhaps, she simply misread her peer's post. But either way, she is experimenting with ways to re-connect with a reader in writing: explain and clarify. And this also illuminates for students one key difference between spoken language and written text: absence of tone and intonation. The experienced writer knows that the author's intent can easily get lost in typeface. Here, novice writers get to experience this for themselves - in future, perhaps bje1486 and Rosie will more carefully consider how their words are read, as opposed to spoken, something markedly different about online discussion in comparison to classroom discussion. This is one of the great benefits of using online social media: it merges the rhetorical goals of writing and speaking, public and private. In a sense, this type of discussion is "writing out loud," similar to thinking out loud as one might do in the classroom discussion, but with the added benefit of time for reflection and revision, greater consideration and adaptation.

Quite naturally, with hardly any influence from me other than the original assignment, they have created their own public forum to exchange ideas, debate, discuss. Eventually, they come to several agreements, a consensus, about the text(s) and about the nature of politics. This was particularly exciting to watch given the ongoing presidential election. These students are all first-year college students, all first time voters, all between the ages of 18-20. The depth of analysis and synthesis surrounding election events was truly amazing. These students are thinking critically about real events that will have a real effect on their lives, and effectively expressing thinking in writing. These students are shaping themselves (and each other) into concerned, actively political citizens. Democracy in action!

The above sample took place in the middle of the semester. A few weeks later, the election would be decided and most of them voted -hopefully due in part to their participation in a democratic public forum. Yet, the excerpts demonstrate that students become thoughtful participants in academic discourse when given the opportunity to do so. They blogged, they thought, they blogged more. What I particularly like about these selections is the reasoning used in support of their claims. Students use references from both assigned texts and their own experiences to support the claims they make. This is precisely the end goal in the first-semester composition course.

Regardless of how each writing teacher chooses to get there, the end result should be the same: By the close of the semester: students should be able to use reason and support their claims with textual and experiential evidence, participating in an ongoing conversation with other academics, on a variety of topics. I have assigned and collected traditional printed-on-paper reader-response type student writing my whole career. Yet, these online versions are vastly superior in the depth of thought demonstrated, in the acknowledgment and anticipation of a real audience, and in the respectful inter-textual conversation (both between/among individual students and between students and text). They are doing it. They are participating in an ongoing academic discourse that looks back toward collective and individual data while looking forward to a responsive interlocutor. They are becoming academic writers and public (literally) intellectuals.

I believe this is possible in an online public forum for several reasons. First, students are well aware of the fact that their peers and their teacher will be reading and evaluating their posts. In traditional paper-based response or journal writing, only the teacher sees their work in most cases. Nothing is more motivating to the human psyche than direct comparison to one's peers. Second, the exchange is genuine. Whereas in paper-based writing, students are expected to anticipate the needs of a reader, that reader is absent and distant from the text and therefore hard to conceptualize. In the online forum, students very quickly figure out how their language is interpreted by others 
and adapt accordingly. Third, Generation M students are already adept at communicating online and thinking intertextually, as demonstrated by the inclusion of hyperlinks to outside images and texts. This medium allows them to execute those already acquired skills for a specific academic purpose. In other words, any instructor can confirm that it's not always easy to engage first-year students in the importance and purpose of properly citing sources in academic writing. But this age group seems to know instinctively, that if they want someone to see or read a reference, they should include the hyperlink. Once they discover this for themselves, it is relatively easy to illustrate the purpose and conventions of referencing sources for an academic reader. As educators know, effective instruction helps students connect the dots between what they already know and what we want them to be able to do on paper... and online.

An additional reason that might explain the effectiveness of this assignment is that these students were already engaging in this type of online forum. I am completely speculating here, because I have no idea how much or how little my students spent online outside of class for social purposes. However, it seems like a fair assumption that the Web 2.0 bug has bitten this particular group as deeply as any of their generational peers. I did not have to do any significant instruction in how to post in an online forum. They already knew.

\section{| Composition 2.0: A Digital Manifesto}

Lately, the conversation in composition studies and in academia at large (a quick search revealed similar conversations in far reaching disciplines like Art, Mathematics, Medicine, Physical Education, Economics, Foreign Language, Political Science, etc.) has turned more and more to using Web 2.0 social networking in the classroom: blogging, Facebook, wikis, YouTube, Twitter, etc. And what used to be cutting edge and forward thinking is now everywhere.... At least everywhere in print - the journals in English and Rhetoric can't stop talking about it. Major national organizations embrace 21st century writing and literacy for annual convention themes: 2008 National Council for Teachers of English was called "When Shift Happens: Teaching in the 21st Century;" the 2009 Modern Language Association Convention chose "The Tasks of Translation in the Twenty-First Century;" and the 2010 Conference on College Composition and Communication was "The Remix: Revisit, Rethink, Revise, Renew." And all of them imply a reinvention on the horizon, a rethinking or reimagining of the ways in which we teach and learn language and literacy. When I talk to fellow Graduate Teaching Assistants and the early-career academics who make up my circle of peers, it seems more of us than not are discussing our students' class blogs, You'Tube videos, or Facebook groups. We all use this media regularly as Gen-Xers and early Millennials so it stands to reason we would feel comfortable, empowered, even obligated to venture into social networking in the classroom space as well. In short, it feels to me like this conversation is everywhere, and therefore, that everyone must be incorporating new media into their teaching.

But then I started wondering, how widespread is this really? Confronted with a professor who called new media pedagogy "cutting edge," I started to wonder if what feels 'normal' and commonplace, is not so after all. I used Facebook to take an informal poll of fellow Rhetoric and Composition specialists, asking them to report on common practices in their own departments: GTAs, adjuncts, full-time faculty, and writing program administrators (WPAs) in an assortment of higher education institutions around the country. Turns out, there is considerable movement toward consciously using online social media in the classroom, but it seems to be coming mostly from the younger members (read: less powerful) of departments. While many young academics are incorporating new media more and more in their classrooms, digital pedagogy is still not sanctioned by departments at large.

Warning: here comes the big pitch. If we take a moment to review the earlier listed goals for the critical rhetoric discourse-studies class (above, p. 9), what is commonly known as first-year English, we will find that every item is addressed in whole or in part in the samples of student online writing above. It was earlier suggested that the field at large anticipates a reinvention on the horizon, a rethinking or reimagining of the ways in which we teach and learn language and literacy. However, while many young academics are incorporating new media more and more in their classrooms, it is not, to my knowledge, currently sanctioned or even formally encouraged by many departments or institutions at large, with several notable exceptions, of course. Yet, in examining my students' online work, this informal study suggests that use of the online social medium produced greater depth of thought, more genuine acknowledgment and anticipation of audience, and more engaged inter-textual conversation than traditional paperbased models. Through this blogging assignment, students created and participated in an ongoing academic discourse that draws on collective and individual knowledge while looking forward to a responsive interlocutor, modeling the 
values of old and new composition at once. And further, even the less advanced student makes significant progress through the course of the semester using an online pedagogical model. The proof is in the pudding.

Now, there are drawbacks and qualifications to be made. I do not mean to suggest that this single assignment, which represents only $20 \%$ of the final grade in the Fall 2008 course, is the end all and be all of composition work. Student success is largely determined by appropriate supporting assignments: good readings, good class discussion, strong major paper assignments, etc. Nor am I suggesting that the online assignment should replace entirely the traditional extended reasoned argument. In my classes, online discussion is currently a tool to reach the same old goal of a well-written, well-argued, researched essay in a primarily face-to-face classroom. However, with such tremendous success in achieving the goals of student writing, it doesn't seem a far leap that composition teachers, indeed all discourse-based instructors, could reap tremendous value from a more purposeful integration of social media in the classroom. It is the interactive, live, self-publishing aspect of this assignment that is the key to its success. Rather than simply talking about or imitating a loose understanding of academic discourse, students get to practice it, to try it on, to see how it feels, all in a cultural medium they are already active participants in (Bartholomae, 1985). And I find that doing so greatly improves their formal written work. But perhaps my favorite part of the whole wonderful enchilada, is the exploration of academic debate and consensus that is central to a strong democracy, a strong educated people. Particularly, the second set of student writing samples, demonstrates the potential for politico-cultural engagement for this generation. I suggest the more critical engagement and academic direction we give students in using online interactive medium, the more consciously involved they become in that medium.

A little discussed benefit for all scholars in this information age is the easy access to quality research and electronic versions of books, both classic and modern. Truth be told, while I read much of the theory for this essay on pulp at some point in my academic career, easily two-thirds of the reference list is locatable in full-text online. We owe it to students to show them how to mine the rich scholarly depth of the deep web (Google Scholar, WorldCat, university databases, and so on) as much as we owe it to them to point out the trappings of less credible sources.

I am certainly not the only compositionist discovering the teaching and learning potential of online social media and calling for change. I am in good company - Lunsford, Yancey, Faigley, Brooke, Hawisher, Selber, Selfe, Vie, and many, many more. What remains is to formally incorporate an active digital pedagogy into our official collection of critical thinking tools. In short, we owe it to this generation and their successors to venture with them toward a revised version of critical thinking pedagogy, Composition 2.0. The only question is how quickly we will embrace the call to reinvent ourselves.

\section{Endnotes}

1. Actually the exact birthday of blogging cannot be pinpointed because in truth, it was a collaborative effort that spanned some fifteen years. However, the people most often cited as the "forefathers" of blogging are Jon Barger, Peter Merholz, Justin Hall, Andrew Sullivan, and Brad Fitzpatrick (McCullagh \& Broache, 2007; Carvin, 2007; Rosenberg, 2009). All but Barger are GenXers and some argue that Barger's weblog is too far removed from the interactive version that defines the medium today (Rosenberg, 2009).
2. I have edited these online postings for clarity and style while maintaining their original intent and meaning. However, it should be noted that formal editing is not a requirement of the blogging assignment and students regularly make errors in spelling and grammar. Because the genre of blog comments often overlook formal English grammar, I do not stress it in this environment either, respecting the generally accepted conventions of the genre. We do discuss the benefit of using proper grammar even online, as a reflection of ethos and credibility. 


\section{References}

Agger, Ben. (Forthcoming). Blogging toward utopia: Reading the MySpace generation.

Agger, B. (1990). Decline of discourse (1st ed.). Falmer Press.

Bartholomae, D. (1985). Inventing the University. In V. Villanueva (Ed.), Cross-Talk in Comp Theory: A Reader (2nd ed., pp. 623-54). Urbana, IL: NCTE.

Barton, M. D. (2005). The future of rational-critical debate in online public spheres. Computers and Composition, 22(2), 177-190. doi: 10.1016/j.compcom.2005.02.002.

Benkler, Y. (2006). The wealth of networks: how social production transforms markets and freedom. New Haven [Conn.]: Yale University Press.

Birkenstein, C., \& Graff, G. (2007). “They say / I say”: The moves that matter in persuasive writing. W.W. Norton \& Co.

Brooke, C. G. (2006). Authorship and Technology. In T. H. Carrick \& R. M. Howard (Eds.), Authorship in Composition Studies, Wadsworth series in composition studies; (pp. 89-100). Australia ; Boston, MA: Thomson/Wadsworth.

Carvin, A. (2007, December 24). Timeline: The Life of the Blog: NPR. NPR.org. Retrieved March 29, 2010, from http://www. npr.org/templates/story/story.php?storyId $=17421022$

Delpit, L. (2006). Other people's children: Cultural conflict in the classroom. New Press.

Derrida, J. (1967). The exorbitant. In The Norton anthology of theory and criticism. Ed. Vincent B. Leitch. New York: W.W. Norton, 2001. 1824-1830.

Dewey, J. (1998). Experience and education (60th ed.). Kappa Delta Pi Pubns.

Ducate, L. C., \& Lomicka, L. L. (2008). Adventures in the blogosphere: from blog readers to blog writers. Computer Assisted Language Learning, 21(1), 9-28. doi: 10.1080/09588220701865474.

Faigley, L. (1997). Literacy after the revolution. College Composition and Communication, 30-43.

Ede, L., \& Lunsford, A. (1984). Audience Addressed/Audience Invoked: The Role of Audience in Composition Theory and Pedagogy. College Composition and Communication, 35(2), 155-171. doi: $10.2307 / 358093$.

Eighner, L. (1994). On Dumpster Diving. In Kirszner, L. G., \& Mandell, S. R. (2007). The Blair Reader: Exploring Contemporary Issues (6th ed.). Prentice Hall.

Grey, D. (n.d.). Counting Eskimo Words for Snow. Language in Use [online]. Retrieved May 11, 2009, from http://www.putlearningfirst.com/language/research/eskimo.html.
Habermas, J. (1991). The Structural Transformation of the Public Sphere: An Inquiry into a Category of Bourgeois Society (1st ed.). Cambridge, Mass: MIT Press.

Hansford, D., \& Adlington, R. (2009). Digital spaces and young people's online authoring: Challenges for teachers. Australian Journal of Language \& Literacy, 32(1), 55-68. doi: Article.

Hawisher, G. E., Selfe, C. L., Moraski, B., \& Pearson, M. (2004). Becoming literate in the information age: Cultural ecologies and the literacies of technology. College Composition and Communication, 642-692.

Jacobs, L. (2008, September 2). Eighner, "Dumpster Diving." Discussion topic. Revisionary.edublogs.org. Message posted to http://revisionary.edublogs.org/ general-comments/1301-syllabus/discussion-page/ prior-discussions $/$ ?topic $=1410$

Jacobs, L. (2008, September 30). RJ\#5 Huxley "Propoganda Under a Dictatorship.” Discussion topic. Revisionary. edublogs.org. Message posted to http://revisionary.edublogs. org/general-comments/1301-syllabus/discussion-page/ prior-discussions-and-reading-journals- $2 /$ ?topic $=1625$

Jacobs, L. (2008, October 30). RJ \#12:Krauss_History of love_p208-252. Discussion topic. Revisionary. edublogs.org. Message posted to http://revisionary.edublogs.org/general-comments/1301-syllabus / discussion-page $/$ ?topic $=1906$

Jeffrey T. Grabill, \& Hicks, T. (2005). Multiliteracies Meet Methods: The Case for Digital Writing in English Education. English Education, 37(4), 301-311.

King, S. (2002). On Writing. Pocket.

Kirszner, L. G., \& Mandell, S. R. (2007). The Blair Reader: Exploring Contemporary Issues (6th ed.). Prentice Hall.

Krauss, N. (2006). The History of Love: A Novel (1st ed.). W.W. Norton \& Co.

Lunsford, A. A. (2006). Writing, technologies, and the fifth canon. Computers \& Composition, 23(2), 169-177. doi: 10.1016/j.compcom.2006.02.002.

McCullagh, D., \& Broache, A. (2007, March 20). Blogs turn 10--who's the father? Cnet.com. News, . Retrieved March 29, 2010, from http://news.cnet.com/2100-1025_3-6168681. html

Perl, S. (1980). Understanding Composing. College Composition and Communication, 31(4), 363-369. doi: $10.2307 / 356586$

Pullum, G. K. (1991). The Great Eskimo Vocabulary Hoax and Other Irreverent Essays on the Study of Language (1st ed.). University Of Chicago Press. 
Rosenberg, S. (2009). Say everything: how blogging began, what it's becoming, and why it matters (1st ed.). New York: Crown.

Selber, S. A. (2004). Multiliteracies for a Digital Age. Carbondale: Southern Illinois University Press.

Selfe, C. L. (1999). Technology and Literacy in the Twenty-First Century: The Importance of Paying Attention. Carbondale, IL: Southern Illinois University Press.

Sommers, N. (1980). Revision Strategies of Student Writers and Experienced Adult Writers. College Composition and Communication, 31(4), 378-388. doi: 10.2307/356588.
Vie, S. (2008). Digital Divide 2.0: "Generation M" and Online Social Networking Sites in the Composition Classroom. Computers and Composition, 25(1), 9-23. doi: 10.1016/j. compcom.2007.09.004.

Yancey, K. B. (2009). Writing in the 21stCentury (p. 9). Urbana, IL: NCTE.

Yarbrough, S. R. (1999). After Rhetoric: The Study of Discourse Beyond Language and Culture (1st ed.). Southern Illinois University Press. 